\title{
Sequencing-Based Analysis for the Identification of Bacteria Associated with Severe Early Childhood Caries (SECC)
}

\author{
Zarina Zainuddin ${ }^{1}$, Abdul Qahhar Bin Paiman ${ }^{1}$, Yunita Dewi Ardini ${ }^{2}$ \\ ${ }^{1}$ Department of Biotechnology, Kulliyyah of Science, International Islamic University Malaysia Kuantan \\ ${ }^{2}$ Department of Paediatric Dentistry, Kulliyyah of Dentistry, International Islamic University Malaysia Kuantan
}

\begin{abstract}
Severe early childhood caries (SECC) is a microbialinfection that severely compromises the dentition ofyoung children. The aim of this study is toidentify bacteria associated with SECC and compare bacterial species between SECC and caries-free children. Bacterial samples were isolated from dental plaque samples of 3 to 6-yearold preschool children and the status of dental caries at the surface level was evaluated using World Health Organization (WHO) diagnostic criteria for decayed, missing and filled tooth surfaces (DFMS). 30 samples from the interproximal part were collected and genomic DNA was extracted using MasterPure ${ }^{\mathrm{TM}}$ Gram Positive DNA Purification Kit. Polymerase Reaction (PCR) was conducted on the genomic DNA extracted to amplify $16 \mathrm{~S} r R N A$ gene and successfully amplified $16 \mathrm{~S} r R N A$ gene from the samples was sent for sequencing. This research was approved by the IIUM Research Ethic Committee (IREC). Using the selected kit, genomic DNA was successfully extracted and PCR amplification of the bacterial 165 rRNAgeneusing universal bacterial primers was achieved giving a product of $1500 \mathrm{bp}$. Results from sequencing when analysedusing BLAST from the NCBI website, identified bacteria from the genus Vibrio, Haemophilus and Aggregatibacter from SECC samples while for caries-free samples Granulicatella was identified.
\end{abstract}

KEYWORDS: Severe Early Childhood Caries, polymerase chain reaction

\section{INTRODUCTION}

Early childhood caries (ECC) is a dental caries of the primary dentition which affects most population of children world-wide and lead to experience for new lesions in both the primary and permanent dentition for severe cases. ${ }^{1}$ It commonly occurs in children from age 2 to 6 year olds. ${ }^{2}$ Even though many potential caries-causing factors have been identified and studied;some which includes consumption of sugars in food and drink $^{3}$, attitude toward oral hygiene habits ${ }^{4}$ and quantity of resources as well as access to dental staff, yetprevalence of caries is still high which can put children further at risk. The treatment is also difficult to perform as general anaesthesia is needed. ${ }^{5}$ Thus, the government hasthe responsibility to organize any programmes that can contribute to the awareness of social dental care. ${ }^{6}$ As mentioned earlier, besides host and cariogenic diet which can contribute to ECC, there is also the role of infection played by microbiota to make it more effective. The microbiota will produce acid by metabolizing sugar,

Corresponding author:

Yunita Dewi Ardini

Department of Paediatric Dentistry,

Kulliyyah of Dentistry,

International Islamic University Malaysia,

Jalan Sultan Ahmad Shah, 25200 Kuantan, Pahang

Email: dryunita@iium.edu.my which can demineralize tooth structure over time. ${ }^{7}$ Unlike previously thought, there are more complex bacterial species communities involved in the pathobiology of caries. ${ }^{8}$ This is due to the availability of current molecular methods for bacterial identification and enumeration that made it possible to study more precisely the association of microbiota with dental caries using DNA sequence-based assays rather than traditional, culture-based approaches. ${ }^{9}$ For that, this basic research is done as an initial step in exploring more undiscovered microbial community and as a continuous effort in helping to reduce the problems. This project was conducted with the aim to identify and compare bacterial species between SECC and caries-free children among 3 to 6 year old preschool children.

\section{MATERIALS AND METHODS}

\section{Subject Selection}

By using simple random sampling, 30 preschool children with the range of 3 to 6 year olds were recruited from the Brainy Bunchnursery, Indera Mahkota 8, Kuantan, Pahang. They were enrolled as subjects for this study as they met the inclusion criteria which included having full primary dentition, ${ }^{10}$ have not used antibiotics within the last 3 months ${ }^{11}$ and consent for participation was 
obtained from their parents or guardians. The selected children were those with severe early childhood caries (S-ECC) and caries-free, which was determined by the number of decayed teeth. Children with severe caries have cavities in the primary dentition where infected lesions were seen on the tooth surfaces. On the other hand, cariesfree children have no cavities or enamels with white spot lesions, which represents early stages of tooth enamel demineralization. ${ }^{12}$

\section{Sample Collection and Preparation}

Sample was collected in the afternoon after the children had their lunch by swabbing the dental surfaces (buccal), dorsum and interproximal with sterile cotton swab or with sterile toothpicks. The swabbing was done approximately three times (triplicate) following the method by Kanasi et al. ${ }^{11}$ for replication purposes. Then, the cotton swab was immersed and stirred in $750 \mu \mathrm{L}$ of sterile PBS buffer in $1.5 \mathrm{~mL}$ microcentrifuge tube for several times. After arrival at the laboratory, the samples were immediately centrifuged at $13000 \mathrm{rpm}$ for several minutes and the supernatants were discarded. The remaining pellets were stored at $20^{\circ} \mathrm{C}$ prior to genomic DNA extraction.

\section{Amplification of genomic DNA using 16S rRNA Primers}

Genomic DNA extraction was conducted using MasterPure ${ }^{T M}$ Gram Positive DNA Purification Kit and the presence of the extracted DNA was confirmed by running the samples on $1 \%$ agarose gel electrophoresis. Prior to the amplification of genomic DNA, the purity and concentration of DNA was determined using Nanodrop Spectrophotometer (NanoDrop ${ }^{\mathrm{TM}} 1000$, USA). 16S rRNA gene from the extracted DNAwas amplified using forward primer 5'-GGT TAC CTT GTT ACG ACT T-3' and reverse primer 5'-AGA GTT TGA TCC TGG CTC AG-3' [15]. The polymerase chain reaction (PCR) reaction was prepared by adding $10 \mu \mathrm{L}$ of autoclaved distilled water, $5 \mu \mathrm{L}$ of forward primer, $5 \mu \mathrm{L}$ of reverse primer, $5 \mu \mathrm{L}$ of template and $25 \mu \mathrm{L}$ of $2 X$ MyTaq PCR Master Mix.The thermal cycle conditions was programmed as follows: initial denaturation at $94^{\circ} \mathrm{C}$ for 2 minutes, denaturation at $94^{\circ} \mathrm{C}$ for 1 minute, annealing with gradient temperature for 0.5 minutes, extension at $72^{\circ} \mathrm{C}$ for 1 minute, with 30 cycles and final extension at $72^{\circ} \mathrm{C}$ for 10 minutes.Fragment length verification was done via UV transilluminator (Alphalmager ${ }^{T M}$ 2200, Germany) visualization of electrophoresed agarose gel of the PCR product.

\section{Sequencing of PCR products}

Bands with the right size of amplicon ie $1500 \mathrm{bp}$ were purified using PureLink ${ }^{\circledR}$ Quick Gel Extraction Kitand were sent to First Base Laboratories Sdn. Bhd. for sequencing processes. The DNA-sequenced data for all samples were analyzed using BLAST (nucleotide BLAST at http://blast.ncbi.nlm.nih.gov/
Blast.cgi) in NCBI websites. From that, several lists of possible bacteria with identical values were identified.

\section{RESULTS}

A preliminary screening process was made on 50 preschool children of 3 to 6 year olds from the Brainy Bunch Kindergarden, Indera Mahkota 8, Kuantan, Pahang. However, after the screening only 30 of them were selected and enrolled in this project based on two categories; presence of severe early childhood caries (SECC) and free-ECC. Table 1 summarizes the results based on group and gender for prevalence analyses. About $66.7 \%$ of total children have been identified as SECC with $40.0 \%$ boys and $26.7 \%$ girls, while $33.3 \%$ of total children are caries-free with similar percentages for boys and girls (16.7\%). It was also shown that there was a linear relationship and significant interaction of age on effect of caries levels in the presence of plaque. On the other hand, this pattern was not observed for caries-free children (Figure 1).

Table 1: Total SECC and caries-free children

\begin{tabular}{lcc}
\hline & N & Percentage (\%) \\
\hline SECC & 4.95 & \\
Mean age (year) & 12 & 40.0 \\
Boys & 8 & 26.7 \\
Girls & 20 & 66.7 \\
Total SECC & & \\
CF & 4.6 & \\
Mean age (year) & 5 & 16.7 \\
Boys & 5 & 16.7 \\
Girls & 10 & 33.3 \\
Total Free-ECC & & \\
Total & 30 & 100 \\
\hline
\end{tabular}

Notes:SECC $=$ Severe Early Childhood Caries, CF= CariesFree

\section{Amplification of genomic DNA using 165 rRNA Primers}

Figure 2 and 3 show the results of PCR products after running with gel electrophoresis viewed under UV transilluminator. From both figures, successful amplification of 1500 bp16SrRNAgene from selected genomic samples of ECC children and caries-free children was observed. However, the brightness of the band is much influenced by the factor of genomic DNA concentration used as the template. Negative control was included to ensure that the PCR was free from contamination as there was no band at all that can be observed. 


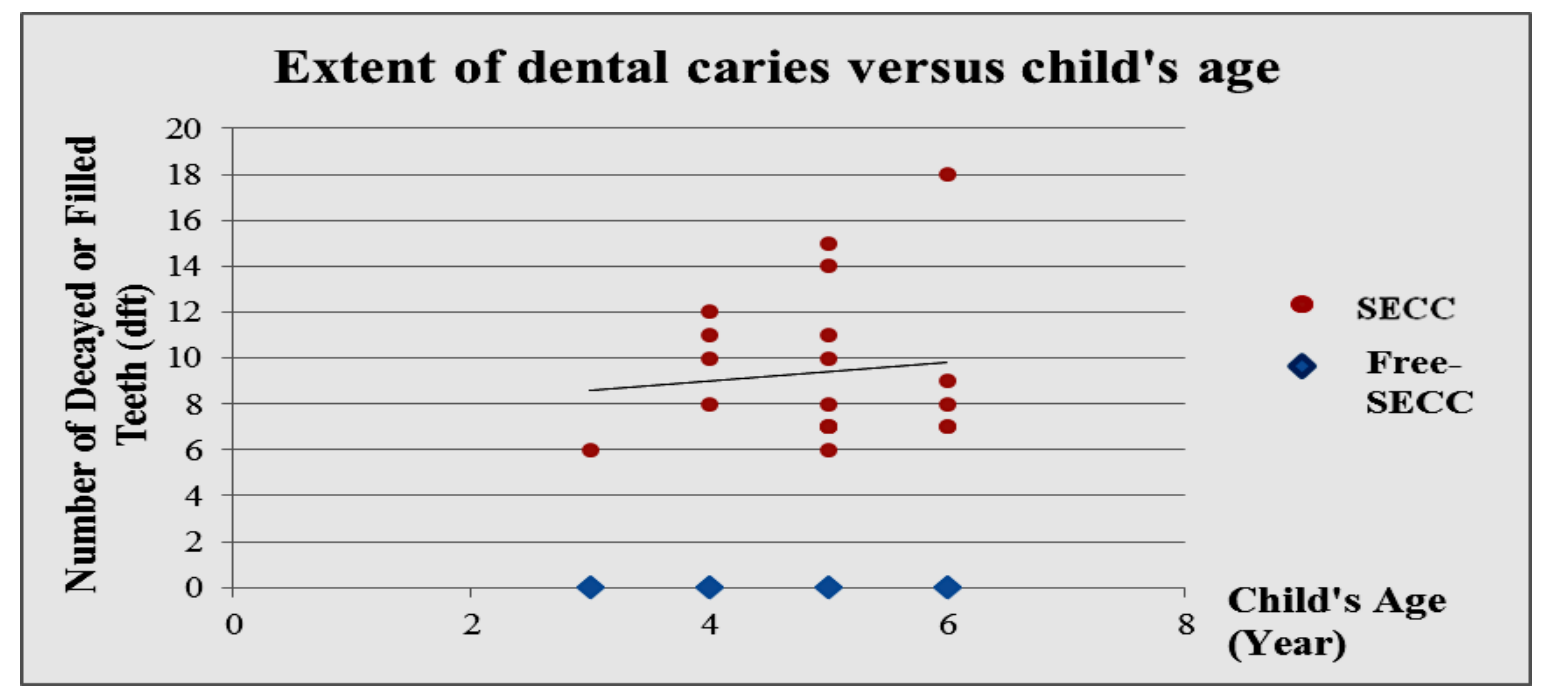

Figure 1: Extent of dental caries (number decayed or filled teeth index) in relation to child's age for SECC and caries-free children.

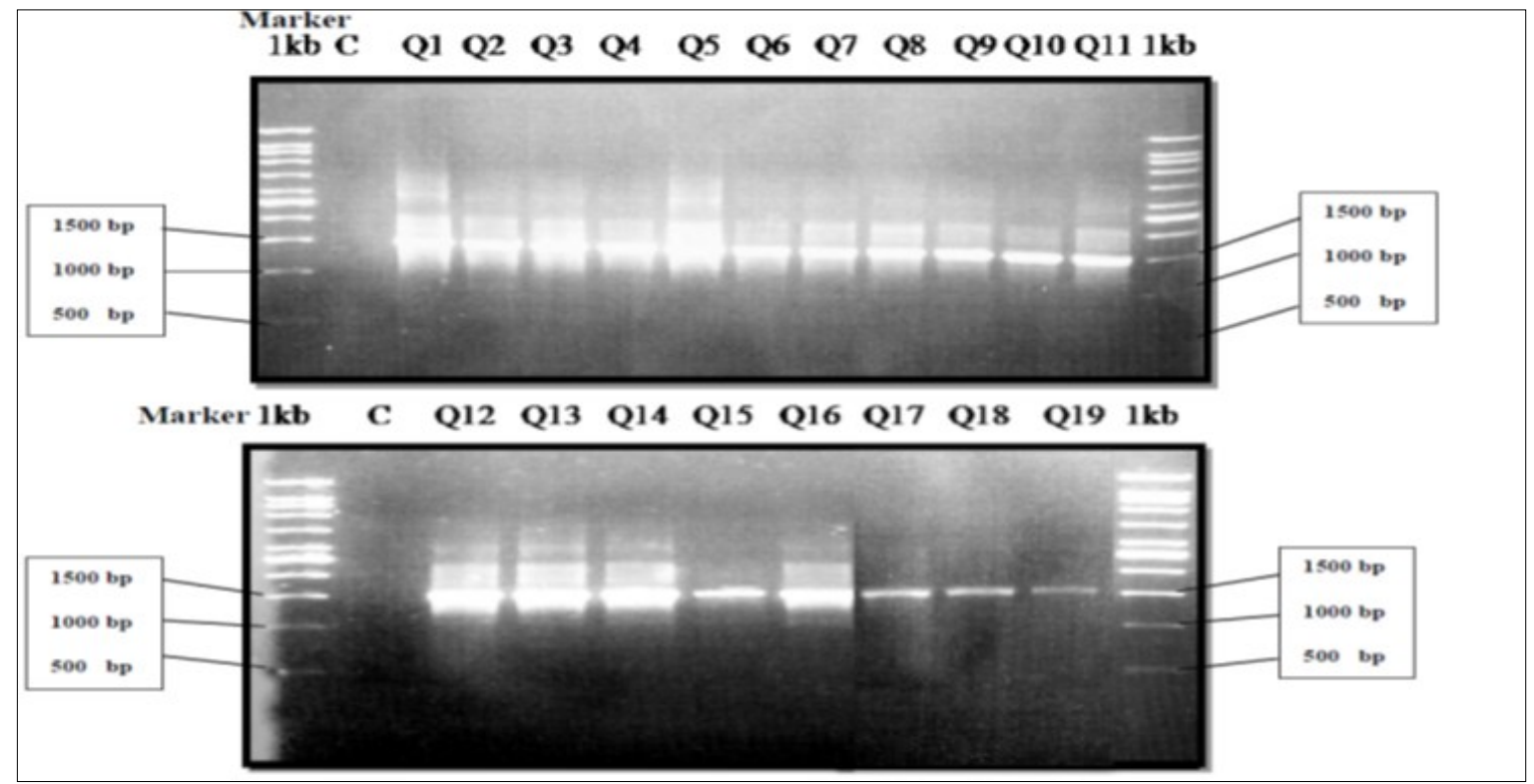

Figure 2: Amplified genomic DNA by PCR for 19 samples (Q1 -Q19) of ECC children. C is the control and $1 \mathrm{~kb}$ ladder was used as DNA marker

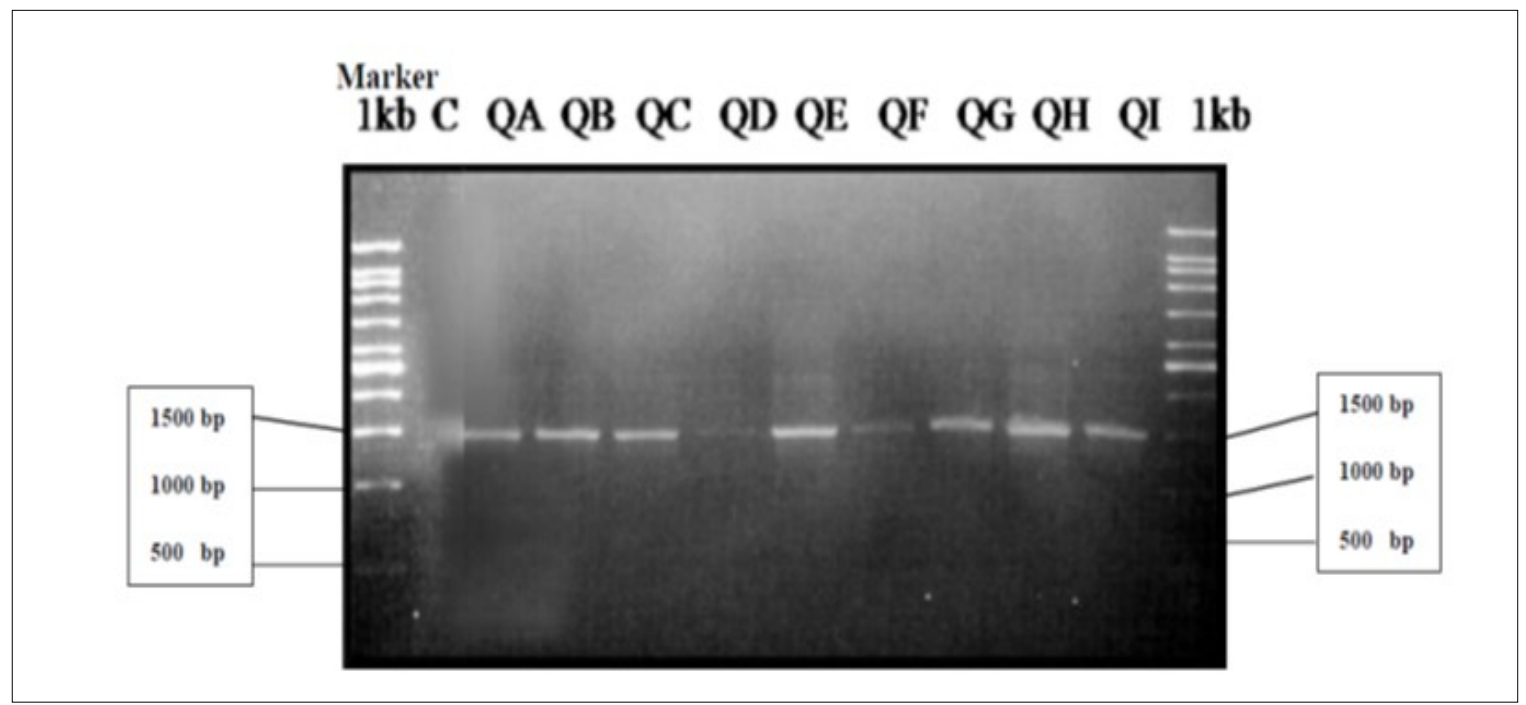

Figure 3: Amplified genomic DNA by PCR for 9samples (QA-QI) of caries-free children. $\mathrm{C}$ is the control and $1 \mathrm{~kb}$ ladder was used as DNA marker. 
Sequencing of PCR products and data analysis in BLAST

3 chosen samples from each category (SECC and caries-free) were sent for sequencing based on the highest top three DNA concentration and the best purity of the samples.For the BLAST analysis, the limit of threshold (above $80 \%$ identical) was set up for the standard reliable results while the lower Evalue indicates the more significant of the result.From the analysis, there was distinct difference between the genus of bacteria present in SECC samples and caries-free samples. Bacteria from the genus Vibrio, Aggregatibacter and Haemophilus were detected in SECC samples while in caries-free samples Granulicatella was identified.

\section{DISCUSSION}

Kanasi et al. ${ }^{11}$ illustrated that age of children plays a significant interaction effect on the extent of caries. Similar results were obtained in this study where the extent of teeth affected by SECC increased with age. When comparison was made between the genus of bacteria present in SECC samples and caries-free samples, a distinct difference can be observed.For SECC samples, the genus of Aggregatibacter was detected suggesting that the genus may be a risk factor for the infection of SECC. However, the result seems opposite to the previous study which concluded that no difference in mean percentages or detection frequencies in the provisional phylotypes between severe ECC and caries-free children. ${ }^{11}$ In this study, Haemophilus genus was also found to be associated with severe ECC, as some studies had confirmed it. ${ }^{5,11}$ It was also known that Haemophilusis one of the prominent plaque bacteria which shared many cross-reacting antigens. Thus, it was referred to as adhesins in deep dental plaque and had the potential to make carbohydrate linkages exposure which subsequently leads to development of caries. ${ }^{12}$ There was very little recordson Vibrio associated with severe ECC. Vibrio was much significant toward causinggingivitis disease than caries especially when there is a combination withSpirochetes. ${ }^{12}$

On the other hand, genus of Granulicatella was resulted from caries-free samples which were contrary to theprevious studies. According to Aas et al. ${ }^{13}$ Granulicatellagenus was highly related to caries disease.

\section{CONCLUSION}

This study was done with the objective of identifying bacteria associated with SECC and to compare bacteria species between SECC and cariesfree children. Successful extraction of genomic DNA and PCR amplification of $16 \mathrm{~S}$ rRNA gene of all the samples were achieved. Purified PCR products were sent for sequencing but accurate identification of the bacteria was not obtained. Failure of obtaining conclusive results might be due to the insufficient purified PCR products' concentration and the impurity presence. Since the genomic DNA yielded was from mix population of bacteria (not from pure culture) the results given by the sequencing company produced many background noises with overlapping peaks that can be seen on the chromatogram. It is undeniable that next generation sequencing (NGS) could overcome this, but the process is too expensive and cannot be done due to limitation of financial resources. Knowledge on bacteria associated with SECC will help dentists to control SECC amongst children in Malaysia.

\section{ACKNOWLEDGMENT}

We would like to acknowledge IIUM for the financial support under grant Endowment $B$.

\section{REFERENCES}

1. Berkowitz, RJ (2003). Causes, Treatment and Prevention of Early Childhood Caries: A Microbiologic Perspective. J Can Dent Assoc; 69(5):304-7.

2. Becker, MR, Paster, BJ, Leys, EJ, Moeschberger, ML, Kenyon, SG, Galvin, JL, Boches, SK, Dewhirst, FE, Griffen, AL(2002). Molecular Analysis of Bacterial Species Associated with Childhood Caries J Clin Microbiol. 40(3): 1001100.

3. Sulinda, D, Marina, M, Rahim Z and Ferguson D (2011). Frequency of Food Intakes and Dental Caries In A Malaysian Dental Student Group. Pak J Med Sci. 27(3):690-692.

4. Umer, A, Umer, A (2011). Oral Health Care In Malaysia - A Review. Pakistan Oral and Dental Journa.l Vol 31, No. 1.

5. Tanner, ACR, Mathney, JMJ, Kent, Jr, RL, Chalmers, NI, Hughes, CV, Loo, CY, Pradhan, N, Kanasi, E, Hwang, J, Dahlan, MA, Papadopolou, E and Dewhirst, FE (2011). Cultivable Anaerobic Microbiota of Severe Early Childhood Caries JClin Microbiol. 49:1464-1474.

6. Edelstein Bl (2000). Access to Dental Care for Head Start Enrollees. J Public.

7. Touger-Decker, R and Van Loveren, C (2003). Sugars and Dental Caries. The American journal of clinical nutrition. 78(4): 881S-892S.

8. Houte, JV, (1994). Role of Micro-Organisms In Caries Etiology J Dent Res.

9. Hugenholtz, P and Pace, N R (1996). Identifying Microbial Diversity in The Natural Environment:A Molecular Phylogenetic Approach. Trends Biotechnol. 14:190197.73:672-681.

10. Palmer, C A, Kent, R, Loo, CY, Hughes, C V, Stutius, E, Pradhan, N, Dahlan, M, Kanasi, E, Arevalo Vasquez, S S and Tanner, A C R 2010. Diet and caries-associated bacteria in severe early childhood caries. J. Dent. Res. 89:12241229.

11. Kanasi, E, Dewhirst, F E, Chalmers, N I, Kent Jr R, Moore, A, Hughes, C V, Pradhan, N, Loo, C Y and Tanner, A C R 2010. Clonal analysis of the microbiota of severe early childhood caries. 
Caries Res. 44:485-497.

12. Liljemark, W F and Bloomquist, C 1996. Human Oral Microbial Ecology and Dental Caries and Periodontal Diseases. Critical Reviews in Oral Biology \& Medicine, 7(2): 180-198.

13. Aas, J A, Griffen, A L, Dardis, S R, Lee, A M., Olsen, I, Dewhirst, F E, Leys, E J and Paster, B J (2008). Bacteria of Dental Caries in Primary and Permanent Teeth in Children and Young Adults. J Clin Microbiol. 46(4): 1407-1417. 
